NBER WORKING PAPER SERIES

\title{
PROTECTION FOR SALE: AN EMPIRICAL INVESTIGATION
}

\author{
Pinelopi Koujianou Goldberg \\ Giovanni Maggi
}

\author{
Working Paper 5942 \\ NATIONAL BUREAU OF ECONOMIC RESEARCH \\ 1050 Massachusetts Avenue \\ Cambridge, MA 02138 \\ February 1997
}

\begin{abstract}
We are indebted to Kishore Gawande and Daniel Trefler for providing us with the data. We also thank Avinash Dixit, Gene Grossman, Jim Harrigan, Mukul Kumar, Andres Rodriguez-Clare, Bob Staiger and seminar participants at Princeton University and the New York Fed for very helpful comments, and Nine Pavcnik for excellent research assistance. During part of this project G. Maggi was visiting at the Economics Department of NYU, which he thanks for the hospitality. This paper is part of NBER's research program in International Trade and Investment. Any opinions expressed are those of the authors and not those of the National Bureau of Economic Research.

(C) 1997 by Pinelopi Koujianou Goldberg and Giovanni Maggi. All rights reserved. Short sections of text, not to exceed two paragraphs, may be quoted without explicit permission provided that full credit, including $(\mathbb{C}$ notice, is given to the source.
\end{abstract}


Protection for Sale: An Empirical Investigation

Pinelopi Koujianou Goldberg and Giovanni Maggi

NBER Working Paper No. 5942

February 1997

JEL No. F1

International Trade and Investment

\section{ABSTRACT}

A prominent model in the recent political-economy literature on trade policy is Grossman and Helpman's (1994) "Protection for Sale" model. This model yields clear predictions for the cross-sectional structure of trade protection. The objective of our paper is to check whether the predictions of the Grossman-Helpman model are consistent with the data and, if the model finds support, to estimate its two key structural parameters: the government's valuation of welfare relative to contributions, and the fraction of the voting population represented by a lobby. We find that the pattern of protection in the U.S. in 1983 is consistent with the basic predictions of the model. Our estimate of the government's valuation of welfare relative to contributions is surprisingly high; the weight of welfare in the government's objective function is estimated to be between 50 and 88 times the weight of contributions.

Pinelopi Koujianou Goldberg

Department of Economics

Fisher Hall

Princeton University

Princeton, NJ 08544-1021

and NBER

penny@phoenix.princeton.edu
Giovanni Maggi

Department of Economics

Fisher Hall

Princeton University

Princeton, NJ 08544-1021 


\section{Introduction}

In the last few years, trade economists have paid increasing attention to the political-economy determinants of trade policies. A prominent model in this recent literature is Grossman and Helpman (1994), which emphasizes the influence exerted by special-interest groups on policy makers by means of political contributions. This is a model with a relatively simple structure that yields clear-cut empirical predictions, and has been applied in a number of subsequent theoretical analyses. When a theoretical framework gains prominence and starts being a tool for further research, it becomes important, we believe, to check how well the model squares with the empirical evidence. The objective of the present paper is to investigate the empirical validity of the Grossman-Helpman (G-H) model.

The G-H model has strong implications for the cross-sectional structure of trade protection. In particular, it predicts that cross-sectional differences in protection should be explained only by three variables: import elasticity, import-penetration ratio, and whether or not the industry is represented by a lobby. In particular: (i) trade protection should be higher in industries represented by a lobby, and in industries with a lower import elasticity, and (ii) conditional on industries being organized, protection should be higher in industries with lower import penetration, whereas in the group of nonorganized sectors, protection should increase with import penetration. We will review the theoretical model and the derivation of these results in the next section.

Strictly speaking we do not test the G-H model, because we do not have a well-specified alternative hypothesis. One possibility would be to take as an alternative the classical optimal-tariff model, in which tariffs are imposed for terms-of-trade reasons. However this model would not have much of a chance, since it is grossly inconsistent with the fact that virtually all countries in the world, no matter how small, have some form of trade protection. Our objective in this paper will simply be to check whether or not the predictions of the G-H model are consistent with the data and, if the model finds support, to estimate its key structural parameters.

In the literature there is a vast number of empirical studies that investigate the political-economy determinants of trade protection. A few examples are Ray (1981), Marvel and Ray (1983), Baldwin (1985), Trefler (1993), and Lee and Swagel (1996). We refer the reader to Rodrik (1995) for a com- 
prehensive survey of this literature. One finding that is fairly consistent across these studies is that trade protection tends to be higher in industries with higher import penetration. This finding seems at odds with the G-H model. ${ }^{1}$ These works, however, take a reduced-form approach, in the sense of not being guided by a theoretical model. The present paper departs from this literature in that we focus on a specific theoretical model, and let our estimations be guided tightly by it. We take the G-H model seriously, in two ways. First, the basic specification includes only the variables that the model suggests are relevant. Second, in estimating the structural relations we utilize the functional forms predicted by the model. We find that this approach produces results that are consistent with the basic predictions of the G-H model.

Like Trefler (1993), we use data on non-tariff barriers for the U.S. in 1983. The model fits the data reasonably well. The coefficient signs are the ones predicted by the model. In particular, we find that the protection pattern differs between politically organized and non-organized sectors: within the group of non-organized sectors, protection tends to increase with import penetration; for organized sectors, on the other hand, there is weak evidence that protection is inversely related to import penetration (the coefficient estimate on the inverse of import penetration is positive, but not statistically significant). We argue that the discrepancy between our findings and those of the aforementioned studies is due to the different way the explanatory variables enter the estimating equation. In particular, the estimating equations employed in previous work typically introduce import penetration and political organization variables additively on the right hand side, whereas we adopt the interactive specification dictated by the $\mathrm{G}-\mathrm{H}$ model.

To further test how closely the model fits the data, we introduce more variables in the estimation, and test whether they add explanatory power to the strict $\mathrm{G}-\mathrm{H}$ model. These are variables commonly used in previous studies for tariff or non-tariff barrier equations (employment size, sectoral unemployment rate, measures of unionization, changes in import penetration, buyer and seller concentration, etc.). The idea is that, if any of these

\footnotetext{
${ }^{1}$ This finding is also inconsistent with several other political-economy models. In his survey of the theoretical political-economy literature, Helpman (1995) shows that a number of existing models, including Mayer (1984), Hillman(1982) and Findlay and Wellisz (1982), predict that trade protection should be higher in industries with lower import penetration - at least this is the case if the models adopt a specific-factors framework.
} 
regressors are found to have additional explanatory power, this may be an indication that the theory provides an incomplete explanation of trade protection, and may suggest in which direction the model could be extended to improve its empirical fit. Strikingly, we find that none of the additional variables improves the explanatory power of the strict $\mathrm{G}-\mathrm{H}$ model, with the possible exception of employment size and unemployment rate (they both have a non-negligible impact on protection, but the formal likelihood ratio test does not reject the simpler specification in favor of the extended one). We also find that an extended specification of the model that allows for endogeneity of the political-organization dummies performs no better than the strict version where these dummies are exogenous.

Another interesting aspect of our exercise is the estimation of the key structural parameters of the model. In particular, we estimate the government's valuation of welfare relative to contributions, and the share of population that is represented by a lobby. Worthy of mention here is that the estimate of the government's valuation of welfare relative to contributions is surprisingly high (the weight of welfare in the government's objective is estimated to be between 50 and 88 times the weight of contributions).

There are two important limitations of this exercise. The first is that we use non-tariff barriers, and in particular coverage ratios, whereas the model's predictions are in terms of tariff levels. The reason we use non-tariff barriers is that tariffs are determined cooperatively in the GATT-WTO, and the model we are focusing on applies to situations where the government sets trade barriers non-cooperatively. In principle, one could attempt to analyze the process of tariff determination by estimating Grossman and Helpman's (1995) "Trade Talks" model, in which governments set tariffs cooperatively. The problem with this approach is that an examination of the empirical implications of the model requires data on political organization variables for the rest of the world; even if it were possible to agree on which countries the "rest of the world" should include, obtaining the necessary information on lobbying and contributions for each country would be extremely hard, if at all feasible.

The problems associated with coverage ratios, and the way we deal with them, are discussed extensively in section 3 . Here we note only a previous result by Trefler (1993) that makes us optimistic about the use of coverage ratios. Trefler constructed coverage ratios for tariffs, and compared them to average tariffs. The correlation coefficient between the two variables was 
$0.78 ;^{2}$ thus the cross-sectional inferences drawn from average tariffs and tariff coverage ratios are very similar. There is a small leap of faith here, but this makes us hopeful that the same thing is true for non-tariff barriers, i.e. that the ranking of sectors in terms of coverage ratios will be close to the ranking of sectors in terms of the actual restrictiveness of trade barriers, so that the use of coverage ratios will not bias the qualitative cross-sectional results. The use of coverage ratios has also the benefit of making our results directly comparable with previous studies, in particular Trefler (1993) and Lee and Swagel (1996).

The second limitation of our exercise is that we do not have reliable data on foreign export supply elasticities. ${ }^{3}$ According to the model, these elasticities incorporate the purely economic determinant of tariffs, namely the terms-of-trade gains from tariffs. In ignoring these elasticities we are effectively making a small-country assumption, which may be controversial in the case of the U.S.. However, we believe that the assumption that a single country does not possess monopsony power is quite realistic for most markets. In the case of the U.S., we feel that this assumption is reasonable with the exception of the market for oil, which is not included in our analysis. ${ }^{4}$

The structure of the paper is as follows. In section 2 we review the G-H theoretical model. In section 3 we describe the econometric specification. In section 4 we describe the data, and the empirical findings. Section 5 concludes.

\section{Review of the Grossman-Helpman model}

In this section we briefly review Grossman and Helpman's (1994) model. We will present a slightly simpler version of the model that yields the exact same predictions. A desirable task would be to identify the weakest assumptions under which the same predictions hold, but we will not pursue this theoretical task here.

\footnotetext{
${ }^{2}$ See Trefler (1993), p. 156.

${ }^{3}$ The available estimates of import demand elasticities are also noisy, although not as much as foreign export supply elasticities. We explain how we deal with this issue econometrically in section 3 .

${ }^{4}$ Our data include only the manufacturing sector, for which, we believe, the assumption of no monopsony power is plausible.
} 
There is a continuum of individuals, and the population size equals one. Individuals have identical preferences, given by

$$
U=c_{0}+\sum_{i=1}^{n} u_{i}\left(c_{i}\right)
$$

where $c_{i}$ denotes consumption of good $i, c_{0}$ denotes consumption of the numeraire good, and $u_{i}$ is an increasing concave function. The demand for good $i$ implied by these preferences is denoted $d_{i}\left(p_{i}\right)$, where $d(\cdot)$ is the inverse of $u_{i}^{\prime}(\cdot)$. The indirect utility of an individual with income $y_{i}$ is given by $V_{i}=y_{i}+\sum_{i=1}^{n} s_{i}\left(p_{i}\right)$, where $s(p)=u(d(p))-p d(p)$.

There are $n+1$ inputs: labor and one sector-specific input for each sector. The total supply of labor has measure one. Good 0 (the numeraire) is produced one-to-one from labor, so that the wage is equal to one. Each of the other goods is produced from labor and the sector-specific input. The returns to specific factor $i$ depend only on $p_{i}$ and are denoted by $\pi_{i}\left(p_{i}\right)$. By Roy's identity, $\pi_{i}^{\prime}\left(p_{i}\right)=y_{i}\left(p_{i}\right)$, where $y_{i}\left(p_{i}\right)$ is the supply function of good $i$.

The government chooses specific trade taxes. A trade tax introduces a wedge between local price and international price: $p_{i}=p_{i}^{*}+t_{i}^{*}$, where $t_{i}^{*}$ represents an import tariff if the good is imported, and a export subsidy if the good is exported. World prices $p_{i}^{*}$ are exogenous. The government redistributes the revenue from trade policy in lump-sum fashion and equally to all citizens (if the revenue is negative, it is financed by lump-sum taxes).

Summing indirect utilities over all individuals, and noting that aggregate income is the sum of labor income, returns to the specific factors and tariff revenue, one obtains aggregate welfare:

$$
W=1+\sum_{i=1}^{n} \pi_{i}+\sum_{i=1}^{n} t_{i}^{s} M_{i}+\sum_{i=1}^{n} s_{i}
$$

where $M_{i}=d_{i}-y_{i}$.

Next we describe the political structure. Suppose that in some subset of sectors $L \subset\{1,2, \ldots n\}$ the owners of specific factors are able to form a lobby. Let $\alpha_{i}$ denote the fraction of people who own specific factor $i$. Assume that each individual owns a unit of labor and at most one type of specific factor. Summing indirect utilities over all individuals who belong to lobby $i$ and rearranging, we obtain lobby $i$ 's aggregate well-being: 


$$
W_{i}=\pi_{i}+\alpha_{i}\left(1+\sum_{j=1}^{n} t_{j}^{s} M_{j}+\sum_{j=1}^{n} s_{j}\right)
$$

Lobby $i$ 's objective is given by $W_{i}-C_{i}$, where $C_{i}$ denotes the contributions paid to the government. The government's objective is a combination of welfare and contributions:

$$
U^{G}=a W+\sum_{i \in L}^{n} C_{i}
$$

where $a$ represents the government's valuation of welfare relative to contributions. ${ }^{5}$

In their original formulation, Grossman and Helpman assume that the interaction between government and lobbies takes the form of a "menu auction", in the sense of Bernheim and Whinston (1986). Here we assume a simpler mechanism that gives rise to the same trade policy outcome: a Nash bargaining game. At the Nash bargaining solution, trade policies are selected to maximize the joint surplus of all parties involved. The joint surplus is given by

$$
\Omega=a W+\sum_{j \in L}^{n} W_{j}
$$

The equilibrium contributions depends in a delicate way on the specifics of the decision-making process and on the parameter values. The model (both in the menu-auction version and in the Nash-bargaining version) yields no simple prediction regarding contributions, except the following: contributions are purely a means to redistribute the surplus between government and lobbies, whereas trade policies are determined to maximize the joint surplus, therefore contributions are in no sense a determinant of trade policy.

To find the equilibrium trade policies, one can rewrite $\Omega$ as:

$$
\Omega=a+\alpha_{L}+\sum_{i=1}^{n}\left(a+I_{i}\right) \pi_{i}+\sum_{i=1}^{n}\left(a+\alpha_{L}\right)\left(t_{i}^{s} M_{i}+s_{i}\right)
$$

\footnotetext{
${ }^{5}$ Grossman and Helpman (1996) show that this objective function emerges in a polit-
} ical system in which lobbies use campaign contributions to influence the outcome of the election, and two parties compete for seats in parliament. 
where $\alpha_{L} \equiv \sum_{i \in L} \alpha_{i}$ represents the share of population that owns some specific factor, and $I_{i}$ is a dummy that takes value one if $i \in L$ and zero otherwise. The first-order condition for tariff $t_{i}^{s}$ is:

$$
\frac{\partial \Omega}{\partial t_{i}^{s}}=\frac{\partial \Omega}{\partial p_{i}}=\left(a+I_{i}\right) X_{i}+\left(a+\alpha_{L}\right)\left[-d_{i}+t_{i}^{s} M_{i}^{\prime}\left(p_{i}\right)+M_{i}\right]=0
$$

which yields:

$$
t_{i}^{s}=\frac{I_{i}-\alpha_{L}}{a+\alpha_{L}} \cdot \frac{X_{i}}{-M_{i}^{\prime}}
$$

The same formula can be expressed in terms of import elasticity and import-penetration ratio:

$$
\frac{t_{i}}{1+t_{i}}=\frac{I_{i}-\alpha_{L}}{a+\alpha_{L}} \cdot \frac{z_{i}}{e_{i}}
$$

where $t_{i}$ is the ad-valorem tariff on good $i, e_{i}$ is the import demand elasticity of $\operatorname{good} i$, and $z_{i} \equiv X_{i} / M_{i}$. Notice that the term $\frac{1-\alpha_{L}}{a+\alpha_{L}}$ is positive: the model predicts that, for organized sectors, the level of protection increases with $X_{i} / M_{i}$. The intuition for this result is that, if domestic output is larger, specific-factor owners have more to gain from an increase in the domestic price, while (for a given import demand elasticity) the economy has less to lose from protection if the volume of imports is lower. Also, sectors characterized by higher import elasticity should receive less protection. The intuition for this is that when the import elasticity is higher, the deadweight loss from protection is higher, hence the government is less willing to grant protection. Finally notice two special cases in which the model predicts free trade. First, if the government does not care about contributions $(a=\infty)$, intuitively it has no incentive to impose trade barriers. Second, if all the voting population is represented by some lobby $\left(\alpha_{L}=1\right)$, then the joint surplus of all lobbies coincides with the well-being of society at large, hence free trade is the equilibrium outcome.

\section{The Econometric Model}

Equation (2) constitutes the basis of our empirical specification. To go from the theoretical model discussed in the previous section to the econometric 
model we estimate, we need to introduce an error term and specify its distribution. This error term can be thought of as a composite of variables potentially affecting protection that may have been left out of the theoretical model, and error in the measurement of the dependent variable. Since the G- $\mathrm{H}$ model is silent about the way the error term should enter the specification, we introduce it in a way that accommodates the estimation. Specifically, after bringing the import demand elasticity on the left hand side of equation (2), we enter the error term additively, so that the estimating equation becomes

$$
\begin{aligned}
\frac{t_{i}}{1+t_{i}} e_{i} & =\frac{I_{i}-\alpha_{L}}{a+\alpha_{L}} \frac{X_{i}}{M_{i}}+\epsilon_{\mathfrak{i}} \\
& =\gamma \frac{X_{i}}{M_{i}}+\delta I_{i} \frac{X_{i}}{M_{i}}+\epsilon_{i}
\end{aligned}
$$

where $\gamma=\frac{-\alpha_{L}}{a+\alpha_{L}}$, and $\delta=\frac{1}{a+\alpha_{L}}$.

Notice the non-additive structure of the relationship predicted by the model: the import penetration ratio (or its inverse, to be more precise) ${ }^{6}$ enters interactively with the political organization dummy. Hence, the model predicts that the relationship between trade protection and import penetration depends critically on whether or not a sector is organized.

Our first task will be to estimate the parameters $\gamma$ and $\delta$ and examine whether their signs are consistent with the theoretical predictions. The G-H model implies that $\gamma\langle 0, \delta>0$, and $\gamma+\delta>0$. Since there is a one-to-one mapping between $\gamma$ and $\delta$ and the structural parameters $a$ and $\alpha_{L}$, we can also use our parameter estimates to compute the implied weight the government attaches to welfare $(a)$, and the fraction of the population represented by a lobby $\left(\alpha_{L}\right)$, and examine whether these figures are within a plausible range.

In order to estimate equation (3), we had to deal with a number of issues having to do with the four variables involved in the equation. In the following we discuss these issues in detail, focusing in sequence on the variables $t_{i}, e_{i}$, $I_{i}$ and $\frac{X_{i}}{M_{i}}$.

\footnotetext{
${ }^{6}$ When we use the term "import penetration" in this paper, we refer to the ratio of imports to domestic output; this use of the term differs from the common definition of import penetration in the literature as the ratio of imports to domestic consumption.
} 


\subsection{Protection measure}

To measure protection we use coverage ratios for non-tariff barriers. Why do we look at non-tariff barriers when the model, strictly interpreted, calls for tariffs? As mentioned in the introduction, a political-economy model with cooperative trade policy determination, like Grossman and Helpman's (1995) "Trade Talks" model, would be more appropriate in explaining the tariff structure in the U.S., but data reasons prevent us from estimating such a model. ${ }^{7}$

Coverage ratios are a notoriously imprecise measure of non-tariff barriers, however there seems to be consensus that, in the absence of reliable numbers on tariff-equivalents, they are the best available measure (see Laird and Yeats (1990) and Trefler (1993) for a detailed discussion). As mentioned in the introduction, the high correlation between tariff coverage ratios and average tariffs documented in Trefler (1993) is encouraging; it suggests that the ranking of sectors in terms of coverage ratios should be roughly the same as their ranking by equivalent tariffs, so that the qualitative cross-sectional findings should not be distorted by the use of coverage ratios.

Our more quantitative findings (in particular, the point estimates of the structural parameters) are certainly affected by the use of coverage ratios. The coverage ratio for industry $i$ is defined as $\sum_{k} n_{k}^{i} w_{k}^{i}$, where the summation is taken over all the products in industry $i,{ }^{8}$ the indicator variable $n_{k}^{i}$ takes value one if product $k$ is covered by some non-tariff barrier, and the weight $w_{k}^{i}$ is the import share of product $k$ relative to total imports in the industry.

\footnotetext{
${ }^{7}$ One possibility, that we have not pursued, would be to use some total index of protection that combines tariffs and non-tariff barriers to estimate the "Protection for Sale" model. The problem with this exercise is that it is not clear how to aggregate price measures with non-price measures. At any rate, we note that tariffs in the U.S. are very low (the average tariff is ca. $5 \%$ ) and vary little across sectors, whereas non-tariff barriers are higher (the average coverage ratio in our data is $13 \%$ ) and vary considerably across sectors. In addition, we suspect that coverage ratios understate the actual extent of protection (see the discussion in this section); thus the discrepancy between the magnitude of tariff and non-tariff protection may be even larger. For these reasons, we feel that accounting for tariffs would not substantially change our qualitative results. An experiment that we did perform was to include tariffs on the right hand side. One would expect that, if the tariff component of protection were important, introducing tariffs as explanatory variables would have a strong effect. But our results were hardly affected by this.

${ }^{8}$ The product here is defined at the most disaggregated level possible, i.e. at the tariffline level. There are around 10,000 products at this level.
} 
Both components of coverage ratios, the weights and the zero-one measures of protection, are problematic. In the following we discuss the problems associated with each component in detail.

Using import shares as weights has the well-known shortcoming of potentially attaching low weight to products that are highly protected, since these sectors are likely to have low imports. However we should point out that this procedure is exactly the same as the one used in the computation of average tariffs; unless one is willing to work at the extremely disaggregate level tariffs are specified at, there is no obvious way to improve on this dimension. Lee and Swagel (1995) provide some encouraging results pertaining to this issue. They constructed average tariffs and coverage ratios for non-tariff barriers using two alternative sets of weights: import shares and production shares. Just as the use of import shares tends to understate protection, the use of production shares should overstate it. The authors report that the correlation between the protection measures obtained by the two different weighting schemes is in the order of .98 .

The second source of imprecision is linked to the use of a zero-one measure of protection for each product. One way to think about this problem is that there are two implicit assumptions in using coverage ratios as the dependent variable. The first one is that coverage ratios of equal magnitude have equal trade-restricting effects; in other words, that there is some monotonic relationship between the coverage ratio and the underlying (average) equivalent tariff. This is a strong assumption, and we have no way of relaxing it. The second assumption concerns the exact nature of this relationship. One option is to assume that for coverage ratios lower than 1 , the coverage ratio reflects the equivalent tariff (meaning, for example, that a coverage ratio of 0.5 corresponds to an equivalent tariff of 0.5 ), and equivalent tariffs higher than $100 \%$ are mapped onto a coverage ratio of 1 . However, the few numbers that are available on equivalent tariffs suggest that this mapping may be understating the extent of protection. As an example consider the automobile industry. Goldberg (1995) estimated the tariff equivalent of the VERs on Japanese imports to be around $60 \%$. In our data, the coverage ratio for autos in 1983 was $7 \%$; this suggests that here the coverage ratio largely understates protection. To address this issue, we allow the equivalent tariff to be a multiple of the coverage ratio (for coverage ratios less than one). In the model estimation, we experiment with different scaling factors, ranging from 1 to 3 . As we will show later, allowing for this scaling factor hardly affects 
the qualitative results; all parameter estimates preserve their signs, and the implied share of the population represented by a lobby remains essentially unaltered. It does, however, affect the implied weight on national welfare; naturally, the higher the scaling factor, the higher our measure of protection, and the lower the implied weight the government attaches to the country's welfare. $^{9}$

Finally, the use of coverage ratios instead of tariffs has implications for the empirical implementation of the model. Given that coverage ratios can only take values between 0 and 1 , the protection variable $t_{i}$ is censored. Accounting for the censoring of the coverage ratios at zero is particularly important, as $39 \%$ of our observations are at zero (in contrast, only one observation is associated with a coverage ratio of 1 ). To this end, the protection equation is specified as a Tobit with double censoring.

\subsection{Elasticities}

Existing estimates of trade elasticities are generally considered unreliable; apart from changing considerably from study to study, they sometimes have the wrong sign, and their standard errors tend to be large. We considered three alternative approaches of dealing with this problem. The first one was to estimate the elasticities ourselves. After reading the existing literature, however, we realized that there was no obvious way to improve on existing estimates. The majority of previous studies have employed sophisticated econometric techniques; the imprecision in the estimates is mainly the result of noisy data, with the noise increasing in the level of disaggregation. Given that we are interested in carrying out the analysis at the most disaggregate level possible, we abandoned this approach. The second alternative was to employ available estimates of trade elasticities, but correct the standard errors of our estimates to take into account the fact that the numbers were

\footnotetext{
${ }^{9}$ Another possible concern with the use of non-tariff barriers is that the cross-sectional predictions of the G-H model may differ according to whether tariffs or quantitative restrictions are used. This is confirmed by Maggi and Rodriguez-Clare (1997), who show that the predictions of the G-H model maychange if quantitative instruments are used and if parameters fall into a certain region. To deal with this concern, we reestimated the model including only price-oriented measures (such as antidumping duties and countervailing duties) in the dependent variable, and we obtained the same qualitative results, as we mention in section 4.3 .
} 
estimated. The main problem with this alternative is that we do not exactly know how the elasticity estimates were obtained in previous studies, and do not have access to the full variance-covariance matrix of the estimates. Moreover, the non-linearity of the model introduced by the truncation of the dependent variable makes the correction extremely complicated if at all feasible. For this reason, we adopted a third alternative: utilize existing trade elasticity estimates, but introduce them on the left hand side of the estimating equation. This way, measurement error in the elasticities is a component of the measurement error in the dependent variable, and will not bias our results, though it may reduce the precision of our estimates.

\subsection{Political-organization dummies}

To construct the political organization dummies, $I_{i}$, we use data on political action committee (PAC) campaign contributions. According to the strict version of the model, one should be able to infer the set of organized industries simply by looking at contribution levels: if the contribution level is positive the industry should be organized. In our data, contribution levels are positive for all 3-digit SIC industries, so that a literal interpretation of the model would imply that all sectors in the economy are organized. However, this implication would be valid only if contributions were made exclusively to influence trade policies, and if they were measured without noise. In reality, firms contribute for a variety of other reasons, in particular to influence domestic policy. Some industries may hire lobbyists to influence domestic policies, but not make an organized effort on the trade front. Moreover there are imprecisions related to the assignment of contributions to 3 -digit industries, so contribution data should be regarded as noisy. ${ }^{10}$ The presence of contributions extraneous to trade policy and of a measurement error calls for a more flexible criterion in assigning the political-organization dummies. We adopted the following intuitive method: if the contribution level was below a certain threshold, the political organization dummy was set to zero; if contributions exceeded the threshold, the dummy was set to one. We first adopted a threshold level suggested by a natural break in the data, then we

\footnotetext{
${ }^{10}$ The original contributions data are at the firm level, and the assignment of firms to 3 digit industries is subject to imprecisions due to the presence of multi-product firms. The reader is referred to the appendix of Gawande's (1995) paper for a detailed description of the way contributions are assigned to industries.
} 
experimented with different levels of the threshold. In section 4.2 . we will be more specific regarding these experiments. ${ }^{11}$

The G-H model takes the level of political organization as given; hence, according to the theory, the organization dummy $I_{i}$ is exogenous. However, since we use contribution data to assign the political organization dummies, and contributions are endogenous in the $\mathrm{G}-\mathrm{H}$ framework, in the empirical implementation of the model we treat $I_{i}$ as econometrically endogenous. To this end, we include a probit equation in our estimating system, with $I_{i}$ as the dependent variable. On the right hand side we include two sets of variables: first, variables that may affect the probability that a sector gets organized (various concentration indices, size of the sector, unionization, etc.); second, factor shares, since these are determinants of import penetration (see discussion below), and the level of import penetration may affect the propensity of a sector to get organized. To examine whether this treatment of $I_{i}$ had an impact on the results, we also estimated a specification in which the political organization dummies were treated as econometrically exogenous; this turned out to make no appreciable difference, either for the point estimates or the standard errors.

\subsection{Import penetration}

Both theory and previous empirical results (Ray 1981, Trefler 1993) suggest that the import-penetration ratio should be treated as endogenous. In the G$\mathrm{H}$ model, trade flows, and hence import penetration, are determined just as in the specific-factors model. Since we are not interested in "testing" the part of the $\mathrm{G}-\mathrm{H}$ model that concerns the determination of trade flows, we specify a reduced form equation for the inverse penetration ratio, that is consistent with the specific factors model. In particular, we employ a specification similar to Trefler's (1993) import equation, where the import penetration ratio is a function of factor shares in each sector. These factor shares are essentially measures of the amounts of capital, land and skilled labor used in each sector. One important difference with respect to Trefler's specification is that we do not directly include protection measures in the import equation, as

\footnotetext{
${ }^{11}$ We should stress an assumption that is implicit in the empirical implementation of the G-H model: the relevant unit for political organization is a 3-digit SIC industry. In other words, we are ruling out that, within the same 3-digit industry, some sub-industries are organized and others are not.
} 
we are not interested in the effects of trade liberalization. We do, however, include all exogenous variables that may indirectly affect protection, through the effect they have on political organization (concentration indices, unionization, etc.). Given that the focus of the paper is on the protection equation and not on the trade equation, the reduced-form specification suffices for our purposes.

\subsection{The full econometric model}

To formalize the discussion above, the empirical model we estimate has the following form:

$$
\begin{gathered}
\frac{t_{i}^{*} e_{i}}{1+t_{i}^{*}}=\gamma \frac{X_{i}}{M_{i}}+\delta I_{i} \frac{X_{i}}{M_{i}}+\epsilon_{i} \\
t_{i}=\left\{\begin{array}{lll}
\frac{1}{\mu} t_{i}^{*} & \text { if } & 0<t_{i}^{*}<\mu \\
0 & \text { if } \quad t_{i}^{*} \leq 0 \\
1 & \text { if } \quad t_{i}^{*} \geq \mu
\end{array}\right. \\
\frac{X_{i}}{M_{i}}=\zeta_{1}^{\prime} Z_{1 i}+u_{1 i} \\
I_{i}^{*}=\zeta_{2}^{\prime} Z_{2 i}+u_{2 i} \\
I_{i}=\left\{\begin{array}{lll}
1 & \text { if } & I_{i}^{*}>0 \\
0 & \text { if } & I_{i}^{*} \leq 0
\end{array}\right.
\end{gathered}
$$

The variable $t_{i}^{*}$ is a latent variable, that can be thought of as the "true" level of protection; this is equal to a multiple $(\mu)$ of the coverage ratio if the coverage ratio is strictly between zero and one. In the implementation of the model, we experiment with $\mu$ values of 1,2 and 3 ; these give us a good sense of the direction in which the results change. Similarly, $I_{i}^{*}$ is a latent variable; if this is positive, the sector is organized, and the organization dummy takes the value 1 ; otherwise the dummy is zero. The vectors $Z_{1 i}$ and $Z_{2 i}$ consist of variables employed in the reduced form specifications for the inverse import penetration ratio and the political organization dummy, respectively. The error terms $\epsilon, u_{1}$ and $u_{2}$ are assumed to be distributed as $N \sim(0, \Sigma)$. 
The system (4)-(8) is estimated by maximum likelihood. To test whether the model predictions are borne by the data, we use three criteria. First, we examine whether the signs of the coefficients $\gamma$ and $\delta$ are the ones predicted by theory. Second, we derive the structural parameters $a$ and $\alpha_{L}$ for various values of the scaling factor $\mu$, and ask whether their values seem plausible, in particular whether $\alpha_{L}$ is between 0 and 1. Third, we successively introduce more variables in the estimation, and test whether these variables have additional explanatory power, in the sense of providing a better fit. These variables consist of the common regressors in tariff or non-tariff barrier equations of previous studies (sectoral employment size and unemployment rate, unionization measures, changes in import penetration, market concentration indices, etc.). In doing this, we depart from the framework of the model, as there is no theoretical foundation for including such variables in the estimation. To the extent that any of these regressors are found to have additional explanatory power, we may get an idea of which aspects of trade protection are incompletely explained by the theory, and in which direction the model should be extended. The results are reported below.

\section{Empirical results}

\subsection{Data}

The static nature of the model calls for a cross-sectional analysis. The data we use in our analysis refer to 1983, and are aggregated up to the 3-digit SIC level. This aggregation level was chosen to match the most disaggregate elasticity estimates available in the literature.

Import demand elasticities are taken from Sheills, Stern and Deardorff (1986), the only study that estimated elasticities at the 3-digit SIC level.

While the estimates present many of the problems discussed above, they were obtained with a sound econometric methodology, and are considered among the most reliable ones in the trade literature.

The inverse import penetration ratio $\left(X_{i} / M_{i}\right)$ is measured as the ratio of value of shipments over imports in each industry. Both series are taken from the NBER Trade and Immigration data file.

Contributions data for the 1981-82 and 1983-84 congressional elections were kindly provided by Kishore Gawande. Given that there is little variation 
in the contribution levels across the two periods, we only use the 1981-82 data in the estimation.

The variables employed in the reduced form equations for the inverse penetration ratio and the political organization dummy were generously provided by Dan Trefler, and we refer the reader to his 1993 publication for a detailed discussion of them (Trefler (1993), Table 1, p. 140, and Data Appendix). The factor share regressors include shares for physical capital, inventories, engineers and scientists, white-collar workers, skilled labor, semiskilled labor, land (cropland, pasture and forest), and subsoil (coa!, petroleum, minerals). The direct determinants of political organization include seller concentration, buyer concentration, seller number of firms, buyer number of firms, minimum efficient scale, capital stock, geographic concentration, unionization, industry unemployment rate ${ }^{12}$ and employment size, tenure and industry growth. The vectors $Z_{1 i}$ (regressors in the import penetration equation) and $Z_{2 i}$ (regressors in the political organization equation) include all of the above variables.

\subsection{Results}

Since the results from the reduced form equations for import penetration and political organization are not interesting per se, we report them in the Appendix (Tables A1 and A2).

The results from estimating the trade protection equation are reported in Table 1. We start by estimating the system (4)-(8). The results we report in this section were derived using a threshold level of $\$ 100,000,000$ in 3-digit industry contributions to assign the political organization dummy. This threshold was chosen because there seems to be a natural break in the data around that point; in particular, there are many sectors contributing $\$ 130,000,000$ and higher, and many sectors contributing $\$ 90,000,000$ or less, but almost none between 90 and 130 million. In the next section we examine the robustness of the results to alternative ways of constructing $I_{i}$.

\footnotetext{
${ }^{12}$ The sectoral unemployment rate is based on data from the March 1983 Current Population Survey (CPS); a worker is considered unemployed in a particular industry, if his/her longest job between March 1982 and March 1983 was in that industry.
} 
Table 1: Results from the Basic Specification (G-H Model)

\begin{tabular}{l|c|r|c|r|rr}
$\mu=1$ & Variable & Coefficient & Standard Error & \multicolumn{1}{c}{$t$} & \multicolumn{2}{|c}{$95 \%$ Confidence Interval } \\
\hline & $\gamma$ & -.0109 & .0043 & -2.558 & -.01948 & -.00247 \\
& $\delta$ & .0111 & .0055 & 2.005 & .00012 & .02198
\end{tabular}

Implied $a: 88$

$\underline{\text { Implied } \alpha_{L}: 0.98}$

\begin{tabular}{l|c|r|c|r|rr}
$\mu=2$ & Variable & Coefficient & Standard Error & \multicolumn{1}{c}{$t$} & $95 \%$ Confidence Interval \\
\hline & $\gamma$ & -.0155 & .0062 & -2.498 & -.02794 & -.00321 \\
& $\delta$ & .0161 & .0080 & 2.008 & .00020 & .03206
\end{tabular}

Implied $a: 61$

Implied $\alpha_{L}: 0.96$

\begin{tabular}{l|c|r|c|r|rr}
$\mu=3$ & Variable & Coefficient & Standard Error & \multicolumn{1}{c|}{$t$} & $95 \%$ Confidence Interval \\
\hline & $\gamma$ & -.0182 & .0073 & -2.462 & -.03288 & -.00354 \\
& $\delta$ & .0193 & .0095 & 2.024 & .00039 & .03823
\end{tabular}

Implied $a: 50$

Implied $\alpha_{L}: 0.94$

Table 1 reports results for three cases: $\mu=1, \mu=2$, and $\mu=3$. In all three cases, the signs and the t-statistics of the coefficients $\gamma$ and $\delta$ are consistent with the predictions of the G-H model. The third sign prediction, $\gamma+\delta>0$, finds weak support. the estimate of $\gamma+\delta$ is positive, but not statistically significant. Hence, our findings support the model's prediction that the relationship between protection and import penetration depends on whether or not the sector is politically organized; the positive sign and the statistical significance of the parameter $\delta$ indicate that there is a distinct pattern of protection in organized versus non-organized sectors. The results 
also support the prediction that the relationship between import penetration and protection is positive within the set of non-organized sectors. The third prediction of the model, that the above relationship is negative within the set of organized sectors, finds only weak support. ${ }^{13}$

These findings invite a comparison with the results of previous empirical work that typically finds a positive correlation between protection and import penetration (e.g. Leamer, 1988, Trefler 1993, Lee and Swagel, 1996). Is there a discrepancy between these results and ours? If so, what are its sources?

We believe that our results are compatible with the ones obtained earlier. When comparing results, however, it is important to note that the estimating equations employed in previous work typically introduce import penetration and political organization variables additively on the right hand side. In the following we argue intuitively that, if the model is true but one uses the additive (mis)specification, one may well find a negative coefficient for $X_{i} / M_{i}$. If the model is true, in the subset of organized sectors we have $\frac{t_{i}^{*} e_{i}}{1+t_{i}^{*}}=(\gamma+$ $\delta) \frac{X_{i}}{M_{i}}$, with $\gamma+\delta>0$, and in the subset of unorganized sectors we have $\frac{t_{i}^{*} e_{i}}{1+t_{i}^{*}}=$ $\gamma \frac{X_{i}}{M_{i}}$, with $\gamma<0$. Now suppose one imposes the additive (mis)specification $\frac{t_{i}^{*} e_{i}}{1+t_{i}^{*}}=\alpha \frac{X_{i}}{M_{i}}+\beta I_{i}+u_{i}$. This amounts to imposing the undue restriction that the coefficient of $\frac{X_{i}}{M_{i}}$ be the same across the two subsets of sectors (organized and unorganized), which implies that the expected estimate of $\alpha$ is some average of $\gamma$ and $(\gamma+\delta)$. Since $\gamma$ and $(\gamma+\delta)$ have opposite sign, for certain configurations of data this average can be negative, while if one utilizes the correct interactive specification one would find a positive coefficient $(\gamma+\delta) .{ }^{14}$

Thus, the positive correlation between import penetration and protection does not constitute evidence against the model. To examine the validity of this interpretation, we estimated the protection equation without interacting

\footnotetext{
${ }^{13}$ There might appear to be an inconsistency between the data and the $\mathrm{G}-\mathrm{H}$ model, in that the model predicts negative protection for unorganized sectors $\left(\frac{t_{i} e_{i}}{1+t_{i}}=\frac{-\alpha_{L}}{a+\alpha_{L}} \cdot \frac{X_{i}}{M}\right.$ if $I_{i}=0$ ), while we do not observe negative protection. But it should be kept in mind that coverage ratios are positive by definition; whether or not there is some form of negative protection for some sectors, the data cannot tell us. On the other hand, the fact that we have a number of unorganized sectors with strictly positive coverage ratios is consistent with the stochastic version of the model (e.g. the presence of an additive error term on the right hand side).

${ }^{14}$ Incidentally, notice that according to our estimates of $\gamma$ and $\delta$, the arithmetic mean of $\gamma$ and $(\gamma+\delta)$ is a negative number.
} 
import penetration with political organization, and did indeed replicate the well documented positive relationship between imports and protection.

The parameter estimates for $\gamma$ and $\delta$ can be used to retrieve the structural parameters $a$ and $\alpha_{L}$. While the credibility of the exact numerical values for these parameters is admittedly low, given the use of coverage ratios instead of tariffs, we think that they may give a rough idea about the magnitude of the true parameters. Naturally, the parameter values depend on the mapping of coverage ratios to equivalent tariffs, reflected in the scaling factor $\mu$. According to the results in Table 1 , if $\mu$ is set to 1 , the weight the government attaches to social welfare $(a)$ is 88 , while the fraction of the population represented by a lobby $\left(\alpha_{L}\right)$ is 0.98 ; if $\mu$ is 2 , the above estimates change to 61 and 96 respectively; for $\mu=3$, they become 50 and 94 , and so on. The way these estimates change as a function of $\mu$ is quite intuitive: the higher $\mu$, the higher the equivalent tariff; this, in turn, implies a lower weight on welfare, and a lower degree of lobby representation. Note that, for all these values of $\mu$, the estimates of the structural parameters lie within the admissible range, as $a$ is positive, and $\alpha_{L}$ is between 0 and 1 , even though we did not impose any restrictions on the empirical specification to guarantee this result. ${ }^{15}$ Even if these numbers are not taken at face value, it seems safe to say that, according to our estimates, the government attaches a non-trivial weight to social welfare and that the degree of lobby representation is high. Our interpretation of these findings is that the United States is relatively open to trade, even when non-tariff barriers are accounted for. The average coverage ratio in our data, for example, is 0.13 , much lower than the potential maximum of 1 . To explain the observed low protection level within the framework of the G-H model, one then needs to appeal to a socially minded government combined with a high degree of representation by interest groups, so that interest groups almost neutralize each other.

Our discussion so far suggests that the empirical results are generally supportive of the theory, in the sense that the variables included in the G-H model are shown empirically to affect protection the way the model predicts they should. Next, we focus on the theoretical implications concerning variables that should not influence protection; the strict interpretation of

\footnotetext{
${ }^{15}$ If $\mu$ is 0.5 , the implied values of the structural parameters are: $a=143, \alpha_{L}=1.001$. This value of $\alpha_{L}$ is slightly off the admissible range. However, we suspect that a value of $\mu=.5$ seriously understates the true level of protection (see discussion in section 3.1 ).
} 
the model implies that once political organization, import penetration and trade elasticities are accounted for, no other observables should help explain protection. To examine this implication, we extend the empirical specification to include variables that may affect protection, but were left out of the model, and test the hypothesis that these variables have additional explanatory power. In the ideal case, these empirical extensions would be guided by well specified alternative hypotheses, suggesting the list of regressors and the functional forms. In the absence of such alternative theories, we rely on findings of earlier studies or simple economic intuition to inform our specifications. The results from this exercise are reported in Table 2 ; since the numerical values of the structural parameters $a$ and $\alpha_{L}$ do not have any meaning in this a-theoretical framework, we concentrate our discussion on the case $\mu=1$ here.

Table 2: Alternative Specifications $(\mu=1)$

Dependent Variable: $\frac{t_{i}^{*} e_{i}}{1+t_{i}^{*}}$

\begin{tabular}{|c|c|c|c|c|}
\hline Variable & $\begin{array}{l}\text { Specification } 1 \\
\text { Log-likelihoor. -is1.08 }\end{array}$ & $\begin{array}{l}\text { Specification } 2 \\
\text { Log:-likelihood: }-131.01\end{array}$ & $\begin{array}{l}\text { Specification } 3 \\
\text { Log-likelihood: }-131.01\end{array}$ & $\begin{array}{l}\text { Specification } 4 \\
\text { Log- ikelihood: }-129.19\end{array}$ \\
\hline$\gamma$ & $\begin{array}{l}-.0109 \\
(.0043)\end{array}$ & $\begin{array}{l}-.0105 \\
(.0045)\end{array}$ & $\begin{array}{l}-.0106 \\
(.0049)\end{array}$ & $\begin{array}{l}-.0100 \\
(.0049)\end{array}$ \\
\hline$\delta$ & $\begin{array}{c}.0111 \\
(.0055)\end{array}$ & $\begin{array}{c}.0111 \\
(.0055)\end{array}$ & $\begin{array}{c}.0111 \\
(.0056)\end{array}$ & $\begin{array}{c}.0108 \\
(.0057)\end{array}$ \\
\hline Constant & - & $\begin{array}{l}-.0442 \\
(.1370)\end{array}$ & $\begin{array}{l}-.0344 \\
(.2134)\end{array}$ & $\begin{array}{r}-.5632 \\
(.3742)\end{array}$ \\
\hline$\Delta$ (import penetration) & - & - & $\begin{array}{l}-.0486 \\
(.8119)\end{array}$ & $\begin{array}{l}.1406 \\
(.8083)\end{array}$ \\
\hline Unemployment & - & - & - & $\begin{array}{c}3.306 \\
(1.970)\end{array}$ \\
\hline Unionization & - & - & - & $\begin{array}{c}.6484 \\
(.7616)\end{array}$ \\
\hline Growth & - & - & - & $\begin{array}{c}.9807 \\
(.7632)\end{array}$ \\
\hline
\end{tabular}


Table 2: continued

Dependent Variable: $\frac{t_{i}^{*} e_{i}}{1+t_{i}^{*}}$

\begin{tabular}{|c|c|c|c|c|}
\hline Variable & $\begin{array}{l}\text { Specification } 5 \\
\text { Log-likelihood: }-227.74\end{array}$ & $\begin{array}{l}\text { Specification } 6 \\
\text { Log-likelihood: }-129.34\end{array}$ & $\begin{array}{l}\text { Specification } 7 \\
\text { Log-likelihood: }-128.26\end{array}$ & $\begin{array}{l}\text { Specification } 8 \\
\text { Log-likelihood: }-125.79\end{array}$ \\
\hline$\gamma$ & $\begin{array}{l}-.0125 \\
(.0049)\end{array}$ & $\begin{array}{l}-.0126 \\
(.0047)\end{array}$ & $\begin{array}{l}-.0123 \\
(.0048)\end{array}$ & $\begin{array}{l}-.0100 \\
(.0058)\end{array}$ \\
\hline$\delta$ & $\begin{array}{l}.0133 \\
(.0059)\end{array}$ & $\begin{array}{l}.0134 \\
(.0057)\end{array}$ & $\begin{array}{l}.0137 \\
(.0058)\end{array}$ & $\begin{array}{l}.0116 \\
(.0071)\end{array}$ \\
\hline Constant & $\begin{array}{l}-.4337 \\
(.4763)\end{array}$ & $\begin{array}{l}-.1614 \\
(.1516)\end{array}$ & $\begin{array}{l}-.4617 \\
(.2569)\end{array}$ & $\begin{array}{l}-1.3587 \\
(1.1572)\end{array}$ \\
\hline Seller concentration & - & - & - & $\begin{array}{c}1.8328 \\
(1.0552)\end{array}$ \\
\hline Seller number of firms & - & - & - & $\begin{array}{c}.1965 \\
(.5924)\end{array}$ \\
\hline Buyer concentration & - & - & - & $\begin{array}{c}.3551 \\
(2.2566)\end{array}$ \\
\hline Buyer number of firms & - & - & - & $\begin{array}{l}.1440 \\
(.2771)\end{array}$ \\
\hline Scale & - & - & - & $\begin{array}{l}-3.2578 \\
(4.6865)\end{array}$ \\
\hline Capital stock & - & - & - & $\begin{array}{l}-.1681 \\
(.5061)\end{array}$ \\
\hline Unemployment & $\begin{array}{c}2.9234 \\
(1.9641)\end{array}$ & - & $\begin{array}{c}2.3294 \\
(1.5884)\end{array}$ & $\begin{array}{c}3.4882 \\
(2.0052)\end{array}$ \\
\hline Unionization & $\begin{array}{l}.6234 \\
(.8093)\end{array}$ & - & - & $\begin{array}{l}.6100 \\
(.8967)\end{array}$ \\
\hline Employment size & $\begin{array}{l}1.3845 \\
(.8436)\end{array}$ & $\begin{array}{l}1.4910 \\
(.8202)\end{array}$ & $\begin{array}{l}1.5714 \\
(.8197)\end{array}$ & $\begin{array}{l}1.6713 \\
(.8663)\end{array}$ \\
\hline Tenure & $\begin{array}{l}-.0363 \\
(.0736)\end{array}$ & - & - & $\begin{array}{l}-.0276 \\
(.0756)\end{array}$ \\
\hline Growth & $\begin{array}{c}.6322 \\
(.7828)\end{array}$ & - & - & $\begin{array}{c}.7764 \\
(.8086)\end{array}$ \\
\hline
\end{tabular}


Table 2 reports results from eight alternative specifications. The first column replicates the results reported earlier from estimating the strict version of the $\mathrm{G}-\mathrm{H}$ model, to provide a standard for comparison. The next columns successively introduce more regressors, starting from a constant term (specification 3), to including changes in import penetration, various measures of employment conditions in the industry, growth, and concentration indices. The striking feature of the results is that none of the alternative specifications is found to significantly improve the fit of the model. Pairwise likelihood ratio tests fail to reject the hypothesis that the restricted version of our empirical model - the one corresponding to the strict interpretation of the G-H model - is the right one. The other interesting feature of Table 2 is that the parameters associated with the variables included in the G-H model $(\gamma$ and $\delta)$ preserve their signs and high $t$-statistics in all specifications.

A closer examination of the results in Table 2 suggests that the only specification that improves the likelihood function by a non-negligible amount, is Specification 7. Even though the formal likelihood ratio test does not reject Specification 1 in favor of 7, the log-likelihood function improves by almost three points, and the three additional regressors are "almost significant". These regressors include in addition to a constant term, the unemployment rate and total employment size of the sector. The signs of both coefficients are intuitive, as one would generally expect sectors providing many jobs to receive more protection, especially when threatened by unemployment. Hence, there is some weak evidence that factors linked to unemployment may affect protection through channels different than the ones suggested by the G-H theory. Presumably, industries that are experiencing high unemployment rates tend to be more vocal in the political arena, and manage to obtain more trade protection. This suggests that it might be fruitful, from an empirical standpoint, to extend the G-H model to allow for sectoral unemployment and examine the impact that this has on the lobbying process.

\subsection{Sensitivity analysis}

In this section we explore the robustness of our findings in four ways. First, we examine whether our results are affected by the presence of elasticities on the left hand side. Second, we consider alternative definitions of the political dummy. Third, we compare the results from our specification, in which the political dummies are treated as endogenous, to a specification that considers 
them econometrically exogenous. Finally, we explore some alternative ways of defining the dependent variable.

As discussed in section 3 , the measurement problems associated with trade elasticities should not bias our results given that elasticities appear on the left hand side of the estimating equation. Nevertheless, to be certain that our findings were not driven by imprecisely measured elasticities, we also estimated equation (4) omitting elasticities from the specification. The signs of the parameters $\gamma$ and $\delta$ remained unchanged, even though their values naturally changed. In addition, we considered two alternative ways of dealing with noisy elasticity values. The first one was to confine estimation to the sectors for which elasticity estimates had plausible sign; this meant eliminating 11, out of 107 sectors, from the estimation. The second approach was to replace elasticity estimates that had the wrong sign (i.e positive import demand elasticities) with negative numbers very close to zero (-0.000001). Both approaches produced estimates that were favorable to the G-H model, and significantly more precisely estimated than the ones reported earlier.

Next, we examined the robustness of our results to different ways of defining the contribution threshold for the construction of the $I_{i}$ dummies, both in terms of units in which we define the threshold, and of the critical level. We tried two alternative measure units, besides the absolute value of each sector's contributions: the share of the sector's contributions in total contributions and the ratio of the sector's contribution to its value added. The alternative threshold levels we experimented with were the following: contribution values of 10 and 50 million dollars, shares of $0.001,0.005$ and 0.01 of the sector in total contributions, and ratios of $0.001,0.005$ and 0.01 of the sector's contribution to its value added. The lower the threshold, the higher the fraction of sectors considered politically organized. While the parameter estimates had in all specifications the expected signs, the precision with which they were estimated declined as the fraction of organized sectors approached the limit of 1 . Intuitively, to identify the parameters of interest $\gamma$ and $\delta$, we need enough variation in the political organization dummy, for the interaction term $\frac{X_{i}}{M_{i}} * I_{i}$ to represent a different regressor from $\frac{X_{i}}{M_{i}}$. Using very low or very high thresholds for constructing the dummy wipes out the variation in the independent variable, increasing the standard errors of our estimates.

We also considered an alternative specification in which contribution levels are directly interacted with the inverse import penetration ratio. This 
specification departs from the theoretical framework, so that the parameters $\gamma$ and $\delta$ have no structural interpretation any more, but it provides a further way of checking whether our results are sensitive to alternative definitions of political organization. To estimate this specification, equations (7) and (8) in the econometric model of section 3 , were replaced by a continuous equation with contribution levels as the dependent variable,

$$
C_{i}=\zeta_{2 c}^{\prime} Z_{2 i}+u_{2 i}
$$

and the estimating equation became

$$
\frac{t_{i}^{*} e_{i}}{1+t_{i}^{*}}=\gamma^{\prime} \frac{X_{i}}{M_{i}}+\delta^{\prime} C_{i} \frac{X_{i}}{M_{i}}+\epsilon_{i}
$$

The results from estimating the modified model, reported in Table 3, are consistent with the ones obtained earlier, indicating that the signs of the parameters $\gamma$ and $\delta$ are not sensitive to the particular way we construct the dummy $I_{i}$.

Table 3: Results from Interacting Contribution Levels with Import Penetration

\begin{tabular}{c|r|c|r|rr} 
Variable & Coefficient & Standard Error & \multicolumn{1}{c}{$t$} & $95 \%$ Confidence Interval \\
\hline$\gamma^{\prime}$ & -.0094 & .0036 & -2.578 & -.0166 & -.0021 \\
$\delta^{\prime}$ & .0025 & .0013 & 1.933 & .0000 & .0051
\end{tabular}

Next, we compared the results we obtained by treating the political organization dummies as endogenous (i.e. system (4)-(8)), to the results from a specification that treats the political dummies as exogenous (i.e. system (4)-(6)). There was hardly a difference; this suggests that thinking of the set of organized sectors as exogenous in the short run, as the $\mathrm{G}-\mathrm{H}$ model does, may be a reasonable abstraction.

Finally, to investigate the robustness of our results to the use of coverage ratios in one more way, we reestimated the model allowing for two different protection equations, one where the dependent variable included only priceoriented non-tariff barriers (anti-dumping duties, countervailing duties) and one where it included quantity measures (quotas, VERs, etc.). The results 
from both specifications were very similar. Moreover, the magnitude of the parameters was quite intuitive; using only price- (or quantity-) oriented NTBs as a measure of protection, produced estimates of the structural parameters $a$ and $\alpha_{L}$ that were much higher than the ones obtained using the composite measure. Intuitively, including only one component of non-tariff protection in the estimation ignores a significant fraction of protection, overestimating the "openness" of the economy; the implied welfare weight is then higher, and so is the estimated degree of lobby representation.

\section{Conclusion}

In this paper we depart from the existing empirical literature on endogenous trade policy, in that we let our estimation be closely guided by a theoretical model. We see three major benefits of this approach. First, of course, this allows a rigorous empirical examination of the model at hand. Second, it allows one to estimate structural parameters, which can contain a great deal of information. Third, and perhaps more importantly, we think there is a value in utilizing a parsimonious model. The spirit of our research has been to look for the "minimal efficient" model among a number of alternative specifications, in the sense of a model that predicts trade protection in the most accurate way with the simplest, theoretically-sound specification. It is striking that the strict version of the Grossman-Helpman model seems quite close to satisfying these requirements.

Adopting a theory-guided approach is important not only because the theoretical model suggests what variables should be included in the regressions and which are endogenous or exogenous, but also because it suggests the way these variables interact with each other, that is, the functional forms that should be utilized. This seems to affect the conclusions about the determination of trade policies. In particular, using the interactive specification suggested by the model, we find that the positive correlation between protection and import penetration documented in previous empirical studies applies only to the group of non-organized sectors. Within the group of politically organized sectors, the point estimate suggests - in line with the theoretical predictions - a negative correlation between the two variables. Even though the latter estimate is not statistically significant, there seems to be a clear difference in the pattern of protection received by the two groups. It is in- 
teresting to note that this difference goes in the direction predicted by the model: it is the non-organized sectors that exhibit the positive correlation between import penetration and protection. For politically organized industries, higher import penetration implies lower protection.

Of some interest, we believe, are also our estimates of two structural parameters, namely the government's valuation of social welfare relative to contributions and the share of population represented by some lobby. Even if our estimated values are not taken at face value, they suggest that social welfare has a substantial weight in the government's objective, and the degree of lobby representation is fairly high. 


\section{Appendix}

Table $A_{1}$ : Reduced Form Equation for Import Penetration

Dependent Variable: Inverse Penetration Ratio $\left(X_{i} / M_{i}\right)$ Number of Observations: 107

$R$-square: 0.49

\begin{tabular}{l|rrr} 
Variable & Coefficient & Standard Error & \multicolumn{1}{c}{$t$} \\
\hline Physical capital & 1296.03 & 435.28 & 2.98 \\
Inventories & -2501.81 & 709.42 & -3.53 \\
Engineers and scientists & -52.79 & 405.38 & -0.13 \\
White-collar & 489.58 & 192.54 & 2.54 \\
Skilled & 91.86 & 252.80 & 0.36 \\
Semiskilled & -99.89 & 202.18 & -0.49 \\
Cropland & 514.86 & 231.45 & 2.23 \\
Pasture & -1493.13 & 366.34 & -4.08 \\
Forest & 4262.02 & 3451.79 & 1.24 \\
Coal & 3043.31 & 3356.99 & 0.91 \\
Petroleum & 5.62 & 154.04 & 0.04 \\
Minerals & -4778.79 & 4020.54 & -1.19 \\
Seller concentration & -37.46 & 56.29 & -0.67 \\
Seller number of firms & -5.64 & 28.03 & -0.20 \\
Buyer concentration & -78.17 & 114.22 & -0.68 \\
Buyer number of firms & -2.35 & 12.76 & -0.18 \\
Scale & -10.80 & 249.05 & -0.04 \\
Capital stock & -118.88 & 42.99 & -2.77 \\
Unionization & 79.64 & 46.55 & 1.71 \\
Geographic concentration & -43.02 & 44.57 & -0.97 \\
Tenure & -.21 & 4.73 & -0.05 \\
Constant & -11.62 & 79.70 & -0.15
\end{tabular}


Table $A_{2}$ : Reduced Form Equation for Political Organization

Dependent Variable: Political Organization Dummy $\left(\mathrm{I}_{\mathbf{i}}\right)$

Number of Observations: 107

Log-Likelihood: -36

Pseudo- $R^{2}: 0.51$

\begin{tabular}{l|rrr} 
Variable & Coefficient & Standard Error & \multicolumn{1}{c}{$t$} \\
\hline Physical capital & 23.90 & 15.25 & 1.57 \\
Inventories & -5.14 & 33.83 & -0.15 \\
Engineers and scientists & 21.03 & 15.73 & 1.34 \\
White-collar & -7.30 & 6.71 & -1.09 \\
Skilled & 22.34 & 10.97 & 2.04 \\
Semiskilled & -18.53 & 7.67 & -2.42 \\
Cropland & 15.57 & 21.13 & 0.74 \\
Pasture & -25.88 & 35.86 & -0.72 \\
Forest & -11.87 & 123.90 & 0.10 \\
Coal & 136.72 & 104.36 & 1.31 \\
Petroleum & 10.45 & 6.06 & 1.73 \\
Minerals & 63.35 & 214.73 & 0.30 \\
Seller concentration & -3.32 & 1.76 & -1.88 \\
Seller number of firms & -1.69 & 1.23 & -1.38 \\
Buyer concentration & 2.13 & 4.27 & 0.50 \\
Buyer number of firms & -.53 & .56 & -.96 \\
Scale & 50.81 & 18.84 & 2.70 \\
Capital stock & -2.83 & 1.51 & -1.88 \\
Unionization & 2.16 & 1.58 & 1.37 \\
Geographic concentration & -3.22 & 1.62 & -1.99 \\
Tenure & -.44 & .16 & -2.73 \\
Constant & 2.59 & 2.92 & 0.89
\end{tabular}




\section{References}

Baldwin, R., The Political Economy of U.S. Import Policy, Cambridge, MA: MIT Press, 1985.

Bernheim, D. and Winston, M., "Menu Auctions, Resource Allocation and Economic Influence," Quarterly Journal of Economics, Vol. 101, 1986, pp. 1-31.

Findlay, R. and Wellisz, S., "Endogenous Tariffs, the Political Economy of Trade Restrictions, and Welfare," Bhagwati, J.N., ed., Import Competition and Response, Chicago: University of Chicago, 1982.

Gawande, K. "Are U.S. Nontariff Barriers Retaliatory? An Application of Extreme Bounds Analysis In the Tobit Model," Review of Economics and Statistics, Vol. 77:4, November 1995, pp. 677-688.

Goldberg, P.K., "Product Differentiation and Oligopoly in International Markets: The Case of the U.S. Automobile Industry," Econometrica, Vol. 63:4, July 1995, pp. 891-951.

Grossman, G. and Helpman, E., "Electoral Competition and Special Interest Politics," Review of Economic Studies, Vol. 63:2, 1996, pp. 265286.

Grossman, G. and Helpman, E., "Trade Wars and Trade Talks," Journal of Political Economy, Vol. 103:4, 1995, pp. 675-700.

Grossman, G. and Helpman, E., "Protection for Sale," American Economic Review, Vol. 84, 1994, pp. 833-850.

Helpman, E., "Politics and Trade Policy," The Sackler Institute for Economic Studies Working Paper No. 30-95, 1995.

Hillman, A., "Declining Industries and Political-Support Protectionist Motives," American Economic Review, 1982, pp. 1180-1187.

Laird, S. and Yeats, A., Quantitative Methods for Trade Barrier Analysis, New York: New York University Press, 1990.

Leamer, E., "Cross-section Estimation of the Effects of Trade Barriers" Feenstra, R., ed., Empirical Methods for International Trade, Cambridge, MA: MIT Press, 1988. 
Lee, J.W. and Swagel, P., "Trade Barriers and Trade Flows Across Countries and Industries," Mimeo, 1996.

Maggi, G. and Rodriguez-Clare, A. "Import Penetration and the Politics of Trade Protection," Mimeo, 1997.

Marvel, H.P. and Ray, E.J., "The Kennedy Round: Evidence on the Regulation of Trade in the U.S.," American Economic Review, Vol. 73, 1983, pp. 190-197.

Mayer, W., "Endogenous Tariff Formation," American Economic Review, Vol. 74, 1984, pp. 970-985.

Ray, E.J., "The Determinants of Tariff and Non-tariff Trade Restrictions in the U.S.," Journal of Political Economy, Vol. 89, 1981, pp. 105-121.

Rodrik, D., "Political Economy of Trade Policy," Grossman, G. and Rogoff, K., eds., Handbook of International Economics, Vol. 3, North Holland, 1995.

Shiells, C., Stern, R. and Deardorff, A., "Estimates of the Elasticities of Substitution between Imports and Home Goods for the United States," Weltwirtschaftliches Archiv, Vol. 122, 1986, pp. 497-519.

Trefler, D., "Trade Liberalization and the Theory of Endogenous Protection," Journal of Political Economy, Vol. 101, 1993, pp. 138-160. 